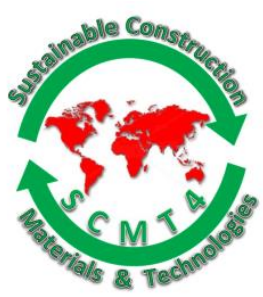

SCMT4

Las Vegas, USA, August 7-11, 2016

\title{
Mechanical Characterization of a New Lightweight Material for Nonstructural Components
}

\author{
Orsola Coppola ${ }^{1 \mathrm{a}}$, Gennaro Magliulo ${ }^{1 \mathrm{~b}}$, and Ernesto Di Maio ${ }^{2}$

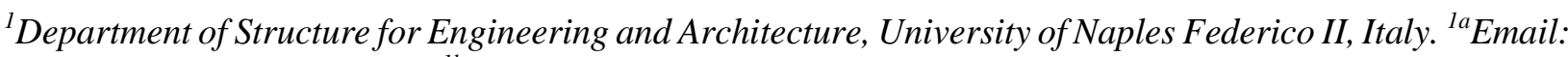 \\ <orsola.coppola@unina.it>, ${ }^{1 b}$ Email: <gmagliul@unina.it>. \\ ${ }^{2}$ Dipartimento di Ingegneria Chimica, dei Materiali e delle Produzione Industriale, University of Naples \\ Federico II, Italy, Email: <edimaio@unina.it>.
}

\begin{abstract}
The mechanical properties of a polyurethane-cement hybrid foam are reported in the paper. The hybrid foam, based on the conjunct use of Portland cement and rigid polyurethane foam, was introduced for applications in the building field. Property of acoustic and thermic insulation, water vapor permeability and the fire resistance were earlier investigated. Here, to evaluate the potential use of this new material in the building field for the seismic protection of nonstructural components, the results of compressive, tensile and shear tests, conducted according to ASTM standards, are reported. The compressive tests showed a brittle behavior of the hybrid foam. Moreover, the material exhibited larger strength in tension than in compression, with a significant strength decay at larger strains. The shear resistance values were similar to those of other materials, i.e. cellular concrete and brick, generally used for infills and internal partitions, usually considered as nonstructural components. Finally, a comparison between the physical and mechanical properties of the material herein studied and those of brick and cellular concrete is made to highlight that the lightweight features of the hybrid foam, associated to appreciable mechanical properties, could make it suitable for building nonstructural components, also in seismic zones.
\end{abstract}

\section{INTRODUCTION}

Nonstructural components, such as internal partitions, infills, cladding panels and ceilings, are recognized to have a significant rule in modern buildings not only because of energy saving, in terms of thermal insulation, but also the seismic performance of such components represents a critical aspect. The seismic response of the buildings is generally influenced by the presence of partitions and infills [Tanganelli et al. 2013, Petrone et al. 2014]; and also in frequent, less intense, earthquakes, the damage of secondary structures can cause a threat to life, the inoperability of the building, and large economic losses [Taghavi and Miranda 2003, Miranda et al. 2012]. For these reasons, in the last years, the selection of internal partitions, infills and cladding panels was done in order to have secondary structures capable of accommodating the deformations of the main structure during an earthquake, without exhibiting significant damage. Modern plasterboard partition systems are currently used in commercial and industrial building, while cellular concrete blocks are becoming frequent both for internal partitions and for external infills in residential buildings, for their lightweight and appreciable mechanical properties. 
Recently, a hybrid material based on the conjunct use of polyurethane and cement was developed [Iannace et al. 2008], in order to obtain a new material able to meet the requirements for architectural nonstructural components in seismic areas, such as low density, strength and ductility, combined to thermal and acoustic features. Polyurethane foams are widely used in in the construction industry for their thermal and acoustic insulation properties, although they are characterized by low strength and stiffness. Cement represents the most widely used structural material, but the high specific weight, the low ultimate strain, the low acoustic and thermal properties make this material unsuitable for architectural nonstructural components.

The new polyurethane-cement hybrid foam optimizes the properties of these two components and at the same time provides a lightweight material. In previous studies [Verdolotti et al. 2008, Verdolotti et al. 2010,Verdolotti et al. 2013] the thermal and acoustic insulation properties of the material are reported.

In this study, a broad mechanical characterization of the hybrid foam is presented, in order to investigate the possible application in the civil buildings field for the seismic protection of nonstructural components.

\section{EXPERIMENTAL INVESTIGATION}

Material. Polyol polyether and diphenylmethane di-isocyanate (MDI) were kindly supplied by Huntsman Tioxide Europe (Ternate, Italy); catalysts, chain extenders, silicone surfactant, flame retardant (Tris (1chloro-2-propyl) phosphate-TCPP) were supplied by Momentive Performance Materials (Germany). Portland cement in powder form, CEM type IIA-S class 42,5R, was used. Distilled water was utilized as chemical blowing agent.

Experimental program. Samples were prepared by mixing at room temperature the cement powder to the polyol with catalysts, silicone surfactant, chain extenders and water as blowing agent. This mixture is stirred mechanically for 2 minutes and then MDI was added and mixed for 40 seconds. Mixing is performed according to ASTM C305 (2014), by a Hobart mixer (mod. N50, Hobart, Canada). According to Iannace et al. (2008), the polyurethane/cement weight ratio was fixed to $2 / 3$. After mixing all the components, the mixture is poured in a wood closed mold $(50 \times 50 \times 5 \mathrm{~cm} 3)$ and the foam is allowed to expand/cure for 20 minutes at room temperature. The sample is then removed from the mold. Samples are then cured in water, for 72 hours at $60^{\circ} \mathrm{C}$, to allow for the hydration of the cement powder.

The chemical, physical and morphological characterization of hydrated samples was reported in a previous publication [Verdolotti et al. 2012]. Here, we focus on specific mechanical properties, namely, compression, tension and shear, which were determined according to ASTM International standard.
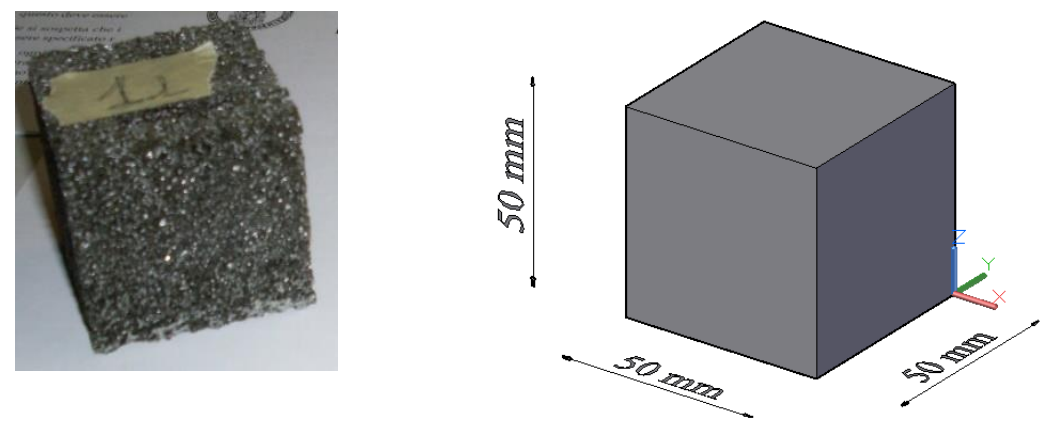

Figure 1. Cubic specimen for compressive tests

Compressive tests. The compressive properties of the polyurethane-cement hybrid foam were evaluated by testing the material according to ASTM D1621-00 (2003). Five cubical specimens with a $50 \mathrm{~mm}$ edge (Error! Reference source not found.a) were cut from a rectangular panel of the hybrid material (Error! Reference source not found.b). A universal electromechanical machine (INSTRON mod. 43258y234, AL, USA) was used to perform tests in displacement control, with a displacement rate equal to $2.5 \mathrm{~mm} / \mathrm{min}$. 
Tensile tests. The ASTM-D1623-03 (2003) was used to evaluate tensile properties of the material. According to this method, the specimens were shaped as shown in Figure 1. The two external conical parts of each specimen are conceived in order to connect the specimen to the testing machine, while the central cylindrical portion represents the length to test.
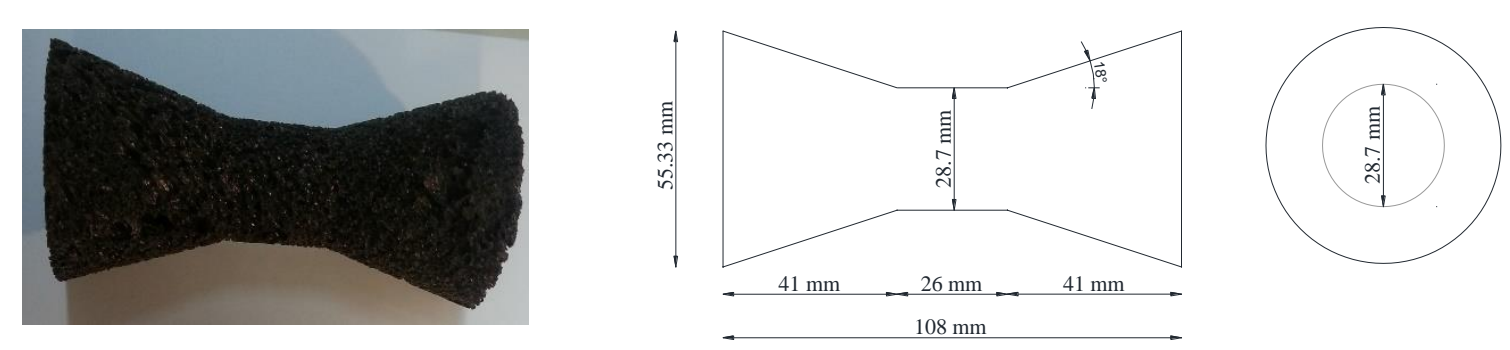

\section{Figure 1. Specimen for tensile tests}

Shear tests. The shear properties of the material are evaluated according to the ASTM-D5379 (2012) According to the test method, a rectangular flat strip specimen, with symmetric centrally located v-notches

Figure 2), is loaded by a special fixture, schematically shown in Error! Reference source not found.
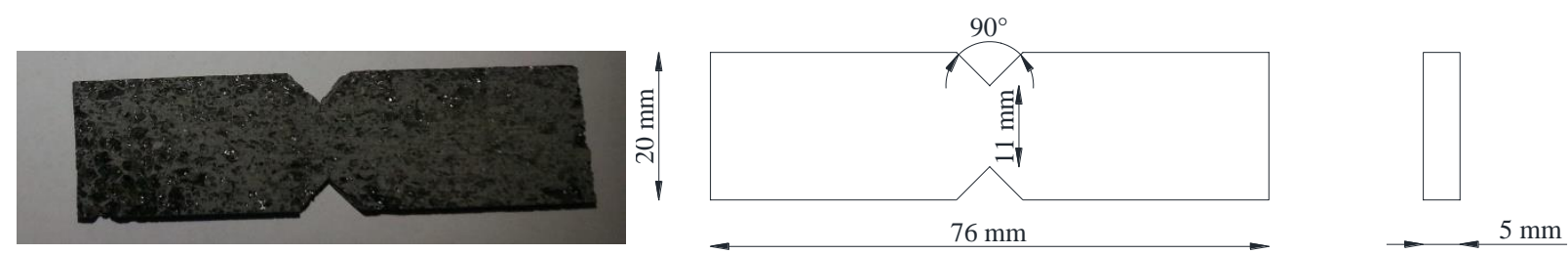

Figure 2. Specimen configuration for shear tests

The specimen was inserted into the fixture with the v-cut located along the loading axis. During the test, the relative displacement between the two fixture halves, loaded the notched specimen. The load scheme, is such that pure shear is recorded in the middle section of the specimen. 


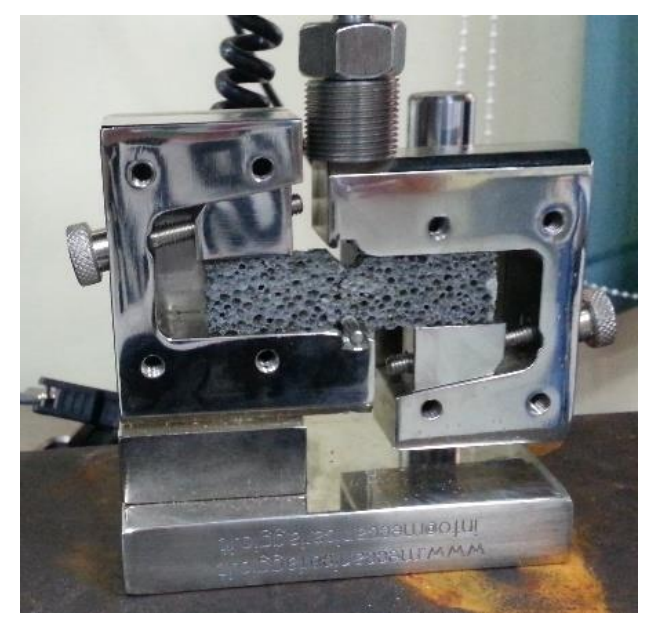

\section{Figure 3. View of the complete setup for the shear test}

The Figure 4 reports a typical test tensile and compressive stress-strain curves of the hybrid foam obtained from the described tests. The compressive curve shows an initial elastic behavior, rather linear, up to the maximum strength of $1.46 \mathrm{~N} / \mathrm{mm}^{2}$ (seeTable 1), beyond which a steep strength reduction of about $40 \%$ occurs, followed by a plastic behavior, with the stress almost constant while the strain increases. It should be noted that the maximum strength is reached for a $1 \%$ strain: this value is larger than the ultimate strain of the concrete (i.e. $0.35 \%$ ), showing a good deformability of this material at the maximum strength. The stress drop observed at $1 \%$ strain is due to the fragile fracture of the hybrid material forming the foam walls/struts. After the fracture of a first (weakest) horizontal section, there is a new stress buildup due to the loading of the other sections, up to the next fracture. This compressive behavior should be classified as microscopically brittle and macroscopically ductile, as the overall strength remains quite constant.

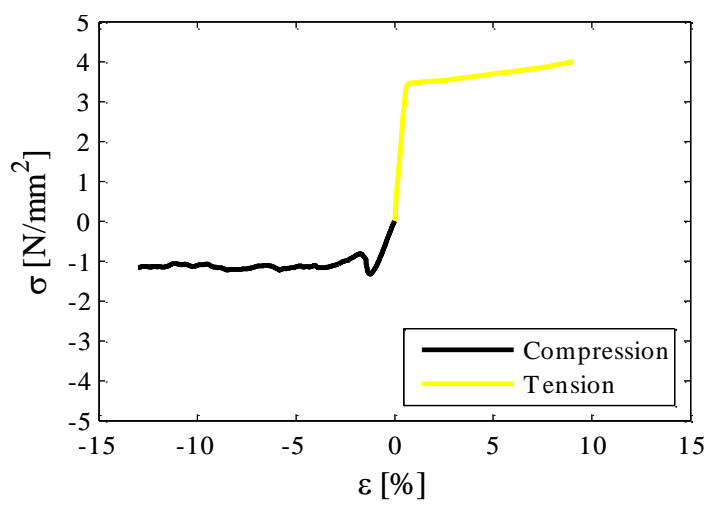

Figure 4. Representative test compressive and tensile stress-strain curves of the hybrid foam

In the tensile region (blue line in Figure 4) of the stress-strain curve, an almost elastic-plastic behavior is evidenced. Larger maximum strength and elastic modulus are recorded in tension, as evidenced in Table 1, than in compression. The presence of the polyurethane phase provides to the hybrid foam a good tensile strength and an appreciable ductility, with respect to a classic or cellular concrete. 
Table 1. Hybrid foam mechanical properties in compression, tension and shear, listed in terms of mean and standard deviation of the test results

\begin{tabular}{|c|c|c|}
\hline \multicolumn{2}{|l|}{ Material } & Hybrid foam \\
\hline Density & {$\left[\mathrm{kg} / \mathrm{m}^{3}\right]$} & 270 \\
\hline Compressive strength & {$\left[\mathrm{N} / \mathrm{mm}^{2}\right]$} & $1.46 \pm 0.21$ \\
\hline Compressive Young's modulus & {$\left[\mathrm{N} / \mathrm{mm}^{2}\right]$} & $144.23 \pm 37.73$ \\
\hline Tensile strength & {$\left[\mathrm{N} / \mathrm{mm}^{2}\right]$} & $4.23 \pm 0.23$ \\
\hline Tensile Young's modulus & {$\left[\mathrm{N} / \mathrm{mm}^{2}\right]$} & $612.05 \pm 18.27$ \\
\hline Shear strength & {$\left[\mathrm{N} / \mathrm{mm}^{2}\right]$} & $0.66 \pm 0.09$ \\
\hline
\end{tabular}

In terms of shear behavior, the experimental force-displacement curve, shown in Figure 5, highlights a linear trend up to the maximum force $(66 \mathrm{~N})$, beyond which a brittle behavior is recognizable. The value of shear strength, i.e. $0.66 \pm 0.09$ strength.

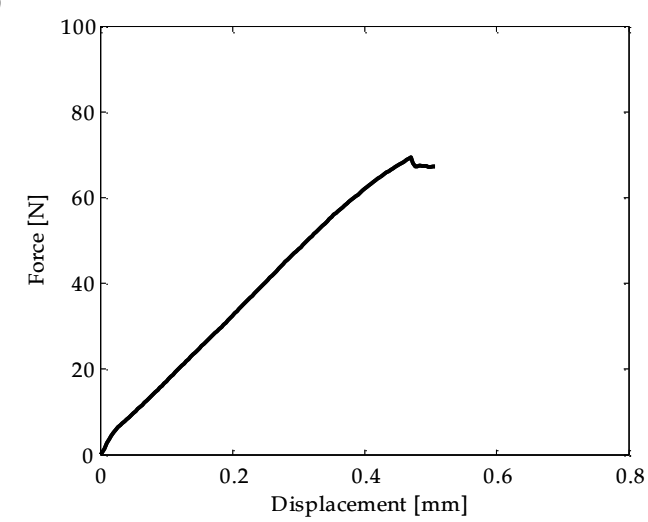

is of compression and tension

Figure 5. Representative test shear force-displacement curve of the hybrid foam

The mechanical properties, in compression, tension and shear achieved by the presented tests allow making a comparison between the material here presented and other materials, generally used for nonstructural components.

In Table 2, the comparison in terms of mechanical and physical properties between the hybrid material and other two materials for architectural nonstructural component use, i.e. brick, largely used in civil applications for infills and internal partitions, and cellular concrete, is made. The choice of these two materials for comparison is not fortuitous, since the hybrid foam could be used in the same field, i.e. for infills and internal partitions of reinforced concrete structures, due to its good adhesion properties to the mortar. In the case of the hybrid foam, indeed, the high concentration of hydrated cement, distributed within the material and on the surface, allows a good adhesion to the mortar.

In comparison with bricks and cellular concrete, the hybrid foam has the lowest specific weight, which is a suitable aspect in seismic field due to the reduction of mass and, consequently, of inertial forces. The lowest Young's modulus in compression proves the hybrid foam to be a more deformable material, which could accommodate the deformations of the hosting structure during the earthquake.

Table 2. Mechanical and physical properties comparison between classic brick, cellular concrete and hybrid foam; (*) typical values 


\begin{tabular}{|l|l|c|c|c|}
\hline \multicolumn{2}{|c|}{ Material } & Brick $\left(^{*}\right)$ & Cellular concrete $\left(^{*}\right)$ & Hybrid foam \\
\hline Volume density & {$\left[\mathrm{kg} / \mathrm{m}^{3}\right]$} & 660 & 575 & 270 \\
\hline Compressive strength & {$\left[\mathrm{N} / \mathrm{mm}^{2}\right]$} & 5.00 & 2.81 & 1.44 \\
\hline $\begin{array}{l}\text { Compressive Young' } \\
\text { modulus }\end{array}$ & {$\left[\mathrm{N} / \mathrm{mm}^{2}\right]$} & 1600 & 2125 & 4.23 \\
\hline Tensile strength & {$\left[\mathrm{N} / \mathrm{mm}^{2}\right]$} & N/A & N/A & 612.05 \\
\hline $\begin{array}{l}\text { Tensile Young' } \\
\text { modulus }\end{array}$ & {$\left[\mathrm{N} / \mathrm{mm}^{2}\right]$} & N/A & $0.20 \div 0.30$ & 0.66 \\
\hline $\begin{array}{l}\text { Shear strength } \\
{\left[\mathrm{N} / \mathrm{mm}^{2}\right]}\end{array}$ & $0.20-1.40$ & $\mathrm{~A} 1$ & $\mathrm{~B} 2$ \\
\hline $\begin{array}{l}\text { Fire reaction (UNI EN } \\
13501-1: 2009)\end{array}$ & {$[$ Euroclass $]$} & $\mathrm{A} 1$ & 50 & 34 \\
\hline $\begin{array}{l}\text { Sound insulation (UNI } \\
\text { ISO 140-1 and 717) }\end{array}$ & {$[\mathrm{dB}]$} & 45 & 0.13 & $0.036-0.046$ \\
\hline Thermal conductivity(l) & {$[\mathrm{W} / \mathrm{m} \mathrm{K}]$} & $0.13-0.21$ & $3.8 \mathrm{E}-08$ & $6 \mathrm{E}-11$ \\
\hline Water vapor permeability & {$[\mathrm{kg} / \mathrm{m} \mathrm{s}$ Pa $]$} & $2 \mathrm{E}-13$ & \\
\hline
\end{tabular}

The hybrid foam shows a lower compression strength with respect the classic brick and the cellular concrete. On the contrary, a good behavior in terms of tension strength was found for the hybrid polyurethane cement foam, even though a direct comparison is not shown in Table 2, because classic brick and cellular concrete tension behavior was not found in literature.

In term of shear strength, the recorded values for the hybrid foam are quite similar to the brick ones and larger than the cellular concrete shear strength. This aspect is fascinating if applications for internal partitions or external infills are thought for the hybrid material: the capacity of accommodating the in-plane deformation of the structure, due to the seismic excitation, increases with the shear strength.

With regard to the physical characteristics, the fire reaction Euroclass of the hybrid material (B2) highlights lower fire resistance features, due to the presence of the polyurethane phase, than the classic brick and the cellular concrete, which are classified as not combustible materials (A1).

The properties of sound insulation are quite comparable between the analyzed materials, even though the polyurethane-cement foam has the lowest value.

The hybrid foam shows very low values of thermal conductivity, lower than that of the traditional lightweight concrete commonly used as insulator (i.e. $0.12 \mathrm{~W} / \mathrm{m} \mathrm{K}$ ). Generally, a decrease of the insulating performances was observed with the increase of the density.

The water vapor permeability value $(6 \mathrm{E}-11 \mathrm{~kg} / \mathrm{m} \mathrm{s} \mathrm{Pa})$, index of the material transpiration, is also consistent with the other ones. The introduction of the cement in the hybrid foam improves the permeability property of the material: as the amount of cement in the hybrid material increases, the water vapor transmission resistance decreases.

\section{CONCLUSION}

The presented work deals with the mechanical characterization of a polyurethane-cement hybrid foam. Compressive, tensile and shear tests are conducted, according to ASTM standard methods for cellular plastic materials, in order to understand the potential use of such a material in the building field. The tests results show that:

- the compressive strength has a $1.4 \mathrm{~N} / \mathrm{mm}^{2}$ medium value and the elastic modulus is $144 \mathrm{~N} / \mathrm{mm}^{2}$, for a $270 \mathrm{~kg} / \mathrm{m}^{3}$ volume density; 
- the polyurethane-cement hybrid foam behaves better in tension than in compression, having a tensile strength of about $4 \mathrm{~N} / \mathrm{mm}^{2}$ and a Young's modulus in tension of $600 \mathrm{~N} / \mathrm{mm}^{2}$; furthermore, a quite elastic-plastic behavior is recognizable from the stress-strain curve;

- a maximum shear strength of $0.6 \mathrm{~N} / \mathrm{mm}^{2}$ is evaluated.

These values, if compared to the corresponding properties of other two materials generally used for architectural nonstructural components, i.e. classic brick widely employed for internal partitions and infills, and cellular concrete, which has nowadays a market expansion, evidence that the hybrid foam is a lightweight material with respect to the brick and the cellular concrete. The mechanical properties values highlight a less resistant and stiff material in compression and a good resistance in tension. The hybrid foam shear strength is greater than the corresponding value of the cellular concrete and very similar to the brick one.

The physical properties of the hybrid foam, such as fire resistance, sound insulation, thermal conductivity and water vapor permeability, are finally compared to those of the other competitor materials. The low thermal conductivity value, i.e. $0.036 \mathrm{~W} / \mathrm{m} \mathrm{K}$, shows good properties of thermal insulation; the water vapor permeability value $(6 \mathrm{E}-11 \mathrm{~kg} / \mathrm{m} \mathrm{s} \mathrm{Pa})$ characterizes a quite transpiring material.

These mechanical and physical properties make the hybrid foam suitable for building partitions and infill, expecially in seismic zones.

\section{ACKNOWLEDGEMENTS}

The financial support of Regione Campania (funds P.O.R. Campania F.S.E. 2007-2013 CUP E65E12000150006) and Hypucem S.r.l. for supplying the materials are gratefully acknowledged.

\section{REFERENCES}

ASTM "American Society for Testing and Materials International " Available at http://www.astm.org/.

C305 (2014). Standard practice for mechanical mixing of hydraulic cement pastes and mortar of plastic consistency. ASTM Volume 04.01.

D1621-00, A. (2003). "Standard Test Method for Compressive Properties Of Rigid Cellular Plastics." Annual Book of ASTM Standard Volume 08.01 Plastics (I).

D1623-03, A. (2003). "Standard Test Method for Tensile and Tensile Adhesion Properties of Rigid Cellular Plastics." Annual Book of ASTM Standard Volume 08.01 Plastics (I).

D5379, A. (2012). "Standard Test Method for Shear Properties of Composite Materials by the V-Notched Beam Method." Annual Book of ASTM Standard Volume 15.03 Space Simulation; Aerospace and Aircraft; Composite Materials.

Iannace, S., E. Di Maio, L. Verdolotti and M. Larvogna (2008). "A foamed polymer-inorganic binder hybrid material having controlled density e morphology, method for its preparation and uses thereof." World Intellectual Property Organization WO 2008/007187 A2.

Miranda, E., G. Mosqueda, R. Retamales and G. Peckcan (2012). "Performance of Nonstructural Components during the 27 February 2010 Chile Earthquake." Earthquake Spectra 28( S1): S453-S471.

Petrone, C., G. Magliulo and G. Manfredi (2014). "Shake table tests for the seismic assessment of hollow brick internal partitions." Engineering Structures 72: 203-214.

Taghavi, S. and E. Miranda (2003). Response assessment of nonstructural building elements, PEER report 2003/05. College of Engineering, University of California Berkeley, USA. . 
Tanganelli, M., S. Viti, M. De Stefano and A. Reinhorn (2013). "Influence of infill panels on the seismic response of existing RC buildings: A case study." Geotechnical, Geological and Earthquake Engineering 24: 119-133.

Verdolotti, L., E. Di Maio, G. Forte, M. Larvogna and S. Iannace (2010). "Hydration-induced reinforcement of polyurethane-cement foams: solvent resistance and mechanical properties." Journal of Materials Science 45: 3388-3391

Verdolotti, L., E. Di Maio, M. Larvogna, S. Iannace and L. Nicolais (2008). "Polyurethane-Cement-Based Foams: Characterization and Potential Uses." Journal of Applied Polymer Science 107 1-8.

Verdolotti, L., E. Di Maio, M. Lavorgna and S. Iannace (2012). "Hydration-induced reinforcement of rigid polyurethane-cement foams: mechanical and functional properties." Journal of Materials Science 47(19): 6948-6957.

Verdolotti, L., M. Larvogna, E. Di Maio and S. Iannace (2013). "Hydration-induced reinforcement of rigid polyurethaneecement foams: The effect of the co-continuous morphology on the thermal-oxidative stabilit." Polymer Degradation and Stability 98: 64-72. 